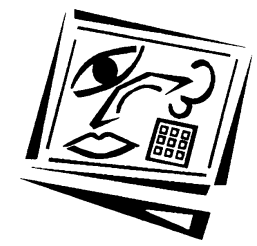

\title{
Adoption of blogging by a Chinese language composition class in a vocational high school in Taiwan
}

\author{
Shi-Jer Lou, Shi-Chiao Wu, Ru-Chu Shih \\ National Pingtung University of Science and Technology \\ Kuo-Hung Tseng \\ Meiho Institution of Technology
}

\begin{abstract}
The purpose of this study was to examine the effect of adopting blogging upon Chinese language composition instruction in a vocational high school in Taiwan. The researchers developed a model that utilises blogging in Chinese language composition instruction. Forty randomly selected students from a public vocational high school served as the research participants. The experimental instruction was employed for eight weeks; all students completed a pre-test before the intervention and a post-test after. Statistical approaches reported include descriptive statistics, a one-sample t-test, and an independent t-test. The results of the study are as follows: (1) the instructional model of utilising blogging in Chinese language composition in a vocational high school can be successfully implemented with positive outcomes; (2) utilising blogging in Chinese language composition instruction can positively enhance students' composition learning; (3) the participants possessed a positive attitude toward the instructional model of utilising blogging in Chinese language composition instruction, and the majority of participants reported feeling positively about the overall design of the blog, the teaching materials, and their own achievement in learning composition; and (4) the instructor-student interaction was positive, which enhances participants' learning motivation and compositional ability.
\end{abstract}

\section{Research background and motives}

Starting in 2010, the entrance examination for two-year and four-year technology colleges in Taiwan, which tests students on many aspects of Chinese culture, will include a composition section, which will represent $24 \%$ of the total score. Because of this significant change in admissions policy, Chinese language instruction that aims to improve language expression ability in vocational high schools has become more important than ever. Due to the limited number of hours spent on Chinese language instruction (approximately 3 or 4 hours every week), the content of and approach to composition instruction should be adjusted to enhance students' composition learning outcomes. Composition is content-rich and transforms one's thinking, imagination, affection, and consciousness into written descriptions; yet, it has been a relatively difficult subject for students. In traditional composition instruction, instructors usually teach structure and sentences. Students then have to create sentences by themselves, connect the sentences, and properly organise them into paragraphs to produce a complete work. Training in thinking and affective expression improves the richness of students' compositional contexts. This training process is usually accomplished in traditional lecture classes. 
As information technology advances, an increasing number of young people have their own blog. Blogs represent "conversation" and there has been a blogging craze in Taiwan since 2005 (Wang, 2007). More and more students now have their own blog and usually leave messages on friends' blogs as well. Message content includes academic learning, personal feelings, personal articles, personal works, and chats with friends. To build on this blogging craze, we aimed to construct a Chinese language composition instructional platform that uses blogs to enhance vocational high school students' composition abilities. The purposes of this study are: 1) to develop an instructional model for utilising blogging in Chinese language composition instruction at a vocational high school; 2) to examine the outcomes of utilising blogging in Chinese language composition; 3) to explore the vocational high school students' learning attitudes toward a Chinese language composition instructional model that utilises blogging; and 4) to investigate vocational high school students' learning processes when taught with a Chinese language composition instructional model that utilises blogging.

\section{Literature review}

\section{Meanings, theories, and related studies on Chinese language composition}

Creation of compositions is the imaginative practice of integrating language, words, and life. Drawing on originality and a depth of language, people record the process of personal growth, which vitalises language use and enriches their lives. Composition is the most realistic record of life, which is the most significant meaning of literature (Hwang, 2005). When people respond to messages delivered creatively, there is an interpersonal interaction that transcends the tangible. Composition is a creative art, and it can connect with people, things, affection, meaning, scenes, and objects. A successful composition can evoke sympathy in readers. As a result, personal feelings can turn into shared experiences. Composition is the combined demonstration of language activity (listening, speaking, reading, and writing), and it can reflect overall language proficiency. Generally speaking, the composition of an article includes three aspects: content, structure or organisation, and sentence-making. These three elements cannot replace one another and are closely related. Articles are the combination of these three elements (Dong, 2001). The basic unit of articles is the sentence. Articles are formed from a single sentence, multiple sentences, and paragraphs composed into chapters. Therefore, to allow readers to clearly understand the messages delivered authors must first create definite sentences.

Composition is one of the best modes of testing students' language expression ability. However, because the content of composition is complex (transforming thinking, imagination, affection, and consciousness into written descriptions), it has typically been a particularly difficult subject for students. In traditional Chinese language composition instruction, instructors usually provide some writing outlines after deciding on the topics and guide students in developing topics and organising paragraphs. However, composition ability is not inherent. The ability to write organised articles with proper language is closely related to the authors' broad reading and practices. Students should recognise how authors express their thoughts and practice imitating their approach to writing. Instructors should instruct students to examine topics, determine the context, select proper materials, and then organise the articles. After learning different writing approaches, students will likely be more interested in composition; this outcome can significantly affect their attitudes toward writing and their future writing ability. 
Regarding studies on Chinese language composition instruction in Taiwan, $\mathrm{Hu}$ (2006) suggested that research directions in the field of composition instruction fall into three categories: "composition content;" "instructional strategy;" and "language cognition." "Instructional strategy" is the most studied of the three (65\%), whereas there are relatively few studies on "language cognition" $(0.06 \%)$. Most studies suggest that altering instructional strategy is the most effective approach to enhance students' composition ability. "Language cognition" has not been valued in composition instruction. $\mathrm{Wu}$ (2009) indicated that the writing of most students includes many misspellings and incorrect uses of idioms and rhetoric. Students' ideas in composition are few in number, and they are uncertain about suitable materials. Most students are dissatisfied with their composition performance and care about their instructors' comments. Most of them enjoy writing and expect to take an increased number of composition-related courses in the future. Therefore, students' Chinese language composition ability will be enhanced if instructors can appropriately guide them, include "composition content" and "language cognition" in teaching materials, provide a composition platform for students' practice and publication, and offer proper feedback and comments.

\section{Characteristics and studies related to blogging instruction}

A blog is a form of personalised online media or a personal online journal that introduces oneself to others, allows individuals to interact with others, and shares personal information, daily activities, and logs. With the convenience, immediate interaction, ability to write and post pictures, and the large volume of blogs, more and more instructors in Taiwan have tried to design instructional platforms using blogging to apply their powerful functions in instruction. In general, the major difference between traditional instruction and blogging instruction of Chinese language composition is that in traditional instruction, the instructor assigns the composition topic, assists students in writing an outline, checks the general order of the content, and has students write the final composition at home.

In blogging instruction, the instructor uses blogs as teaching materials to conduct composition instruction. The blogging platform consists of webpages for a bulletin board, teaching resources, group discussion, work appreciation, and assessment. The instructor uses blogs to guide students' compositions in addition to in class instruction. Blogs also enable students to interact and cooperate with each other. By using blogging composition instruction, the instructor can monitor and understand students' writing processes and offer proper assistance as needed. $\mathrm{Ku}$ (2007) indicated that current education-related blogs include resource integration blogging, instructor-oriented blogging, and student-oriented blogging. The theory of blogging instruction is based on constructivism, where instruction is designed to be learner-centred, trigger students' motivation to learn, provide various learning opportunities for learners' active study, value interaction among colleagues, and adopt interactive instruction and multiple evaluations.

According to interactive learning theory, interaction, which includes interpersonal interaction and interaction between people and teaching materials, is the basis of learning behaviour and enhances learning (Hung, Tan \& Koh, 2006; Kennedy, 2004). Chou and Chang (2002) suggested that in Internet instruction, functions such as email, bulletin boards, chat rooms, and discussion rooms can enhance learner-instructor and learner-learner interactions. Learner-content interactions can be strengthened through multimedia presentations, learners' contributions to learning materials, and links to 
related learning materials. Blogs involve all of the above functions and characteristics. Therefore, blogging instruction should be able to effectively enhance interaction among learners, instructors, and course content. Yang (2007) indicated that some advantages of blogging applications in instruction include: enhancing the exchange between students and instructors, enhancing administration efficiency and school reputation, reducing misspelling and enhancing writing skills, constructing learning files, and creating knowledge. Du and Wagner (2007) also noted that blogs enable people to publish their thoughts as webpages and so share information and knowledge. Due to the potential impact of blogging on knowledge expression and sharing, blogging positively influence instruction and learning (Brownstein \& Klein, 2006; Dippold, 2009; Goldman, Cohen \& Sheahan, 2008).

Regarding studies on blogging instruction, Wang (2006) suggested that Internet-based composition has a number of advantages, including rapid writing, easy modification, easy publication, and immediate interaction. Using blogging in composition instruction is a new approach for composition, especially Chinese composition. To date, little research involving blogging for Chinese composition has been conducted in Taiwan. Research that has been conducted used mainly junior high school and elementary school students and focused primarily on integrating blogging instruction with peer assessment, and integrating composition modes of picture and text transmission on the blogs. These studies have employed experimental teaching and action research to collect data for exploring students' attitudes toward composition, motivation, and learning effects. Results of these studies have indicated that students' attitudes toward composition became more serious and that students' composition performance with peer assessment was superior to the performance of students in the control group. No change in motivation before and after the experiments was found (Cheng, 2008; Liao, 2007; Shih, 2007; Sun, 2008). These studies indicate that blogging can be a suitable approach for composition instruction. However, the question remains whether the characteristics of blogging can be applied to Chinese language composition, and if so, what the outcome and students' attitude would be. Is blogging worthy of being promoted in Chinese society as a method of enhancing students' Chinese language composition ability? These questions require further study.

\section{Research design and implementation}

\section{Experimental design}

The experimental model of this study is shown in Table 1.

Table 1: Quasi-experimental research design

\begin{tabular}{|c|c|c|c|}
\hline & Pre-test & Experimental process & Post-test \\
\hline Participants & $\begin{array}{l}\qquad \mathrm{O}_{1}(\mathrm{x}) \\
\text { Pre-test scores; students' } \\
\text { Chinese language } \\
\text { composition scores before } \\
\text { the experiment. }\end{array}$ & $\begin{array}{l}\text { X } \\
\text { An eight-week experiment of } \\
\text { utilising blogging in Chinese } \\
\text { language composition } \\
\text { instruction. }\end{array}$ & $\begin{array}{l}\qquad \mathrm{O}_{2}(\mathrm{x}) \\
\text { Post-test scores; students' } \\
\text { Chinese language } \\
\text { composition scores after } \\
\text { the experiment. }\end{array}$ \\
\hline
\end{tabular}

\section{Research participants}

The research participants were 40 randomly selected freshman students (16 males, 24 females) at a public vocational high school in southern Taiwan. All students demonstrated average Chinese language abilities and basic abilities in Chinese and 
English typing and computer operation. Some of the participants already had their own blog, which made implementation of the instructional model easier.

\section{Research tools}

The research tools included: 1) a Chinese blogging platform; 2) a self-developed "teaching plan for utilising blogging in Chinese language composition instruction"; 3 ) a "learning satisfaction questionnaire" designed by the researchers; 4) instructors' reflections on their instruction; and 5) a record of the students' learning process. In this study, all activities were conducted in Chinese; the authors have translated any quotes into English. The details of the research tools are described below.

1. The Chinese blogging platform: The blogging platform is in Chinese and has various functions that make it easy to manage and operate, which is very suitable for teaching and learning. Instruction was delivered entirely online. To be effective, the instructor had to become familiar with the operation of the blogging platform, aware of the students' weaknesses, and be able to provide appropriate learning units to assist students' learning. The instructor could comment on students' assignments directly, and the students could go to a forum to comment on each other's works before they had access to other members' profiles.

2. The teaching plan for blogging instruction: The plan is based on the teaching materials of vocational high school students' composition ability that had been designed previously by a Chinese language guidance team at the vocational high school and on the researchers' design and editing. The content included wording and language cognition, use of rhetoric, enhancement of sentences, application of imagination, logical organisation of sentences, cognition of key points of paragraphs, the analysis of meaning, and reflection on writing.

3. The learning satisfaction questionnaire: This questionnaire assessed students' opinions of the overall design of the blogging, the content of blogging composition instruction, the blogging composition instructional model, composition learning attitude, and composition learning outcomes. Items were answered on a five-point Likert scale, where $5=$ strongly agree, $4=$ agree, $3=$ neutral, $2=$ disagree, and $1=$ strongly disagree. One professor and two experienced senior high school Chinese language instructors modified and validated the content of the questionnaire to establish the content validity of the questionnaire. The questionnaire obtained a Cronbach alpha value of.9686, indicating a high reliability of the questionnaire.

4. The instructor's instructional reflection: The researchers recorded the situations encountered with regard to the instruction and students' learning. In addition, instructors wrote about the instructor-learner interaction and personal views on unit learning so that the researchers could analyse these as a set of complete thoughts.

5. The records of the students' learning processes: All data were collected from students' feedback on the use of blogging. These records of students' learning processes, allowed the researchers to understand the students' learning situation and also to test and assess students' performances. 


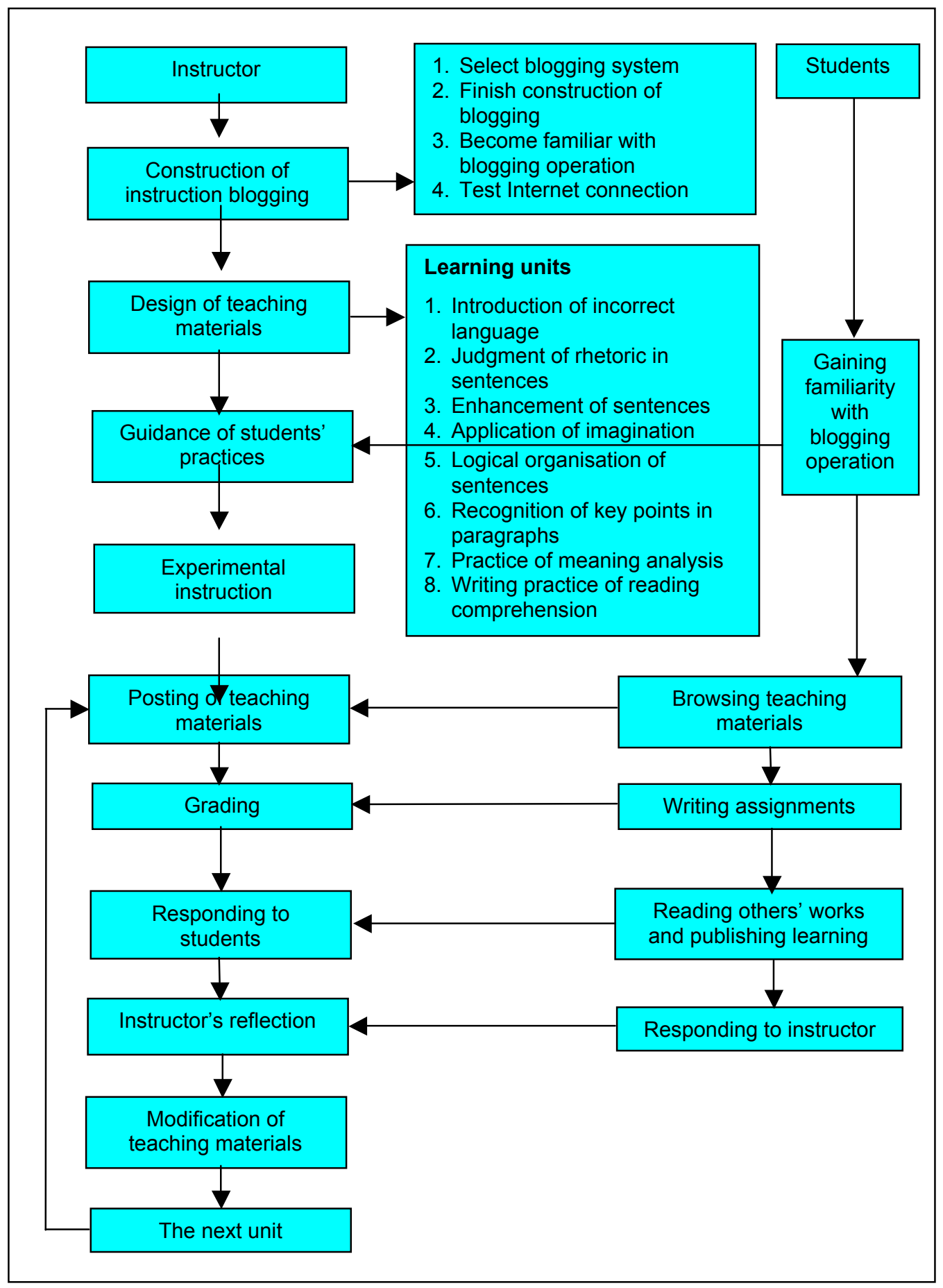

Figure 1: The teaching procedures of the blogging Chinese language composition instructional model 


\section{The blogging Chinese language composition instruction model}

Figure 1 shows the teaching procedures of the blogging Chinese language composition instructional model. Students and instructors interacted in the blogging instruction based on the implementation of procedures and learning units.

\section{Steps in implementing the blogging Chinese language composition instruction}

The steps used to implement the blogging Chinese language composition instructional model were as follows:

a. The first step was to construct a Chinese language composition instructional blog. The blog included functions such as labels, a message board, connection, publication, RSS, and management. Students were able to leave messages and post articles, pictures, and videos. Features of the blog, such as large volume, fast, easy to manage, and free, made the blog suitable for instruction.

b. The instructor created files of students' personal information, teaching materials, and grades, a discussion forum, and practice area in the blog.

c. Before the experiment, the instructor guided the participants on how to use the blog, submit assignments, and post materials on the forum and confirmed that everyone could enter the blog to practise (as shown in Figures 3 to 5).

d. Before receiving blogging instruction, the students took an initial writing test in a narrative or lyric genre to assess their composition ability pre-intervention. Participants were asked to finish one article of about 600 words in 50 minutes. After the test, the instructor and another Chinese language instructor scored the articles. The scoring standard was based on a composition ability index set by the Ministry of Education in Taiwan. The pre-test score was the average of the two raters' scores.

e. The content of the experimental instruction was posted on the blog on different weeks. Content areas included: including wording and language cognition; the use of rhetoric; the enhancement of sentences; the application of imagination; the logical organisation of sentences; the cognition of key points in paragraphs; meaning analysis; and reading reflection.

f. The students were instructed to finish the assigned reading each week, upload the assignments to their personal files, and upload learning reflection or comments on other classmates' works on the forum.

g. After the students uploaded the assignments, the instructor graded them and posted comments or modifications directly on each student's assignments on the webpage. All students could browse both their own and each others' personal files to read the instructor's grades and comments.

h. Grades for each weekly assignment were announced the following week. Students could learn their grade by checking the grade file.

i. After the experimental instruction, a second writing test was employed with a similar writing style and grading process. The average of the two raters' scores was treated as the post-test score. The degree of difficulty in the two tests was similar. 


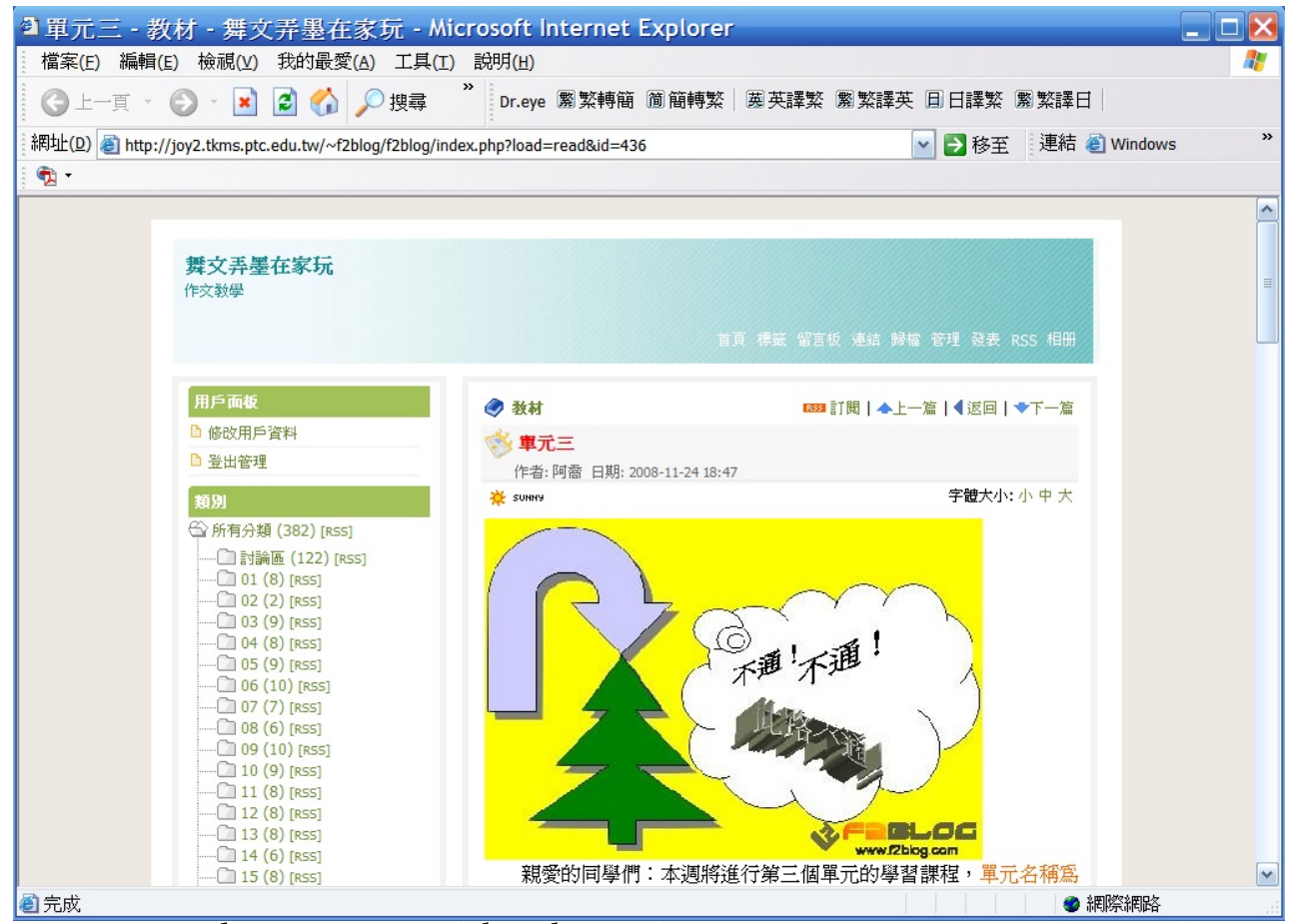

Figure 2: The main page of the Chinese language composition instruction blog

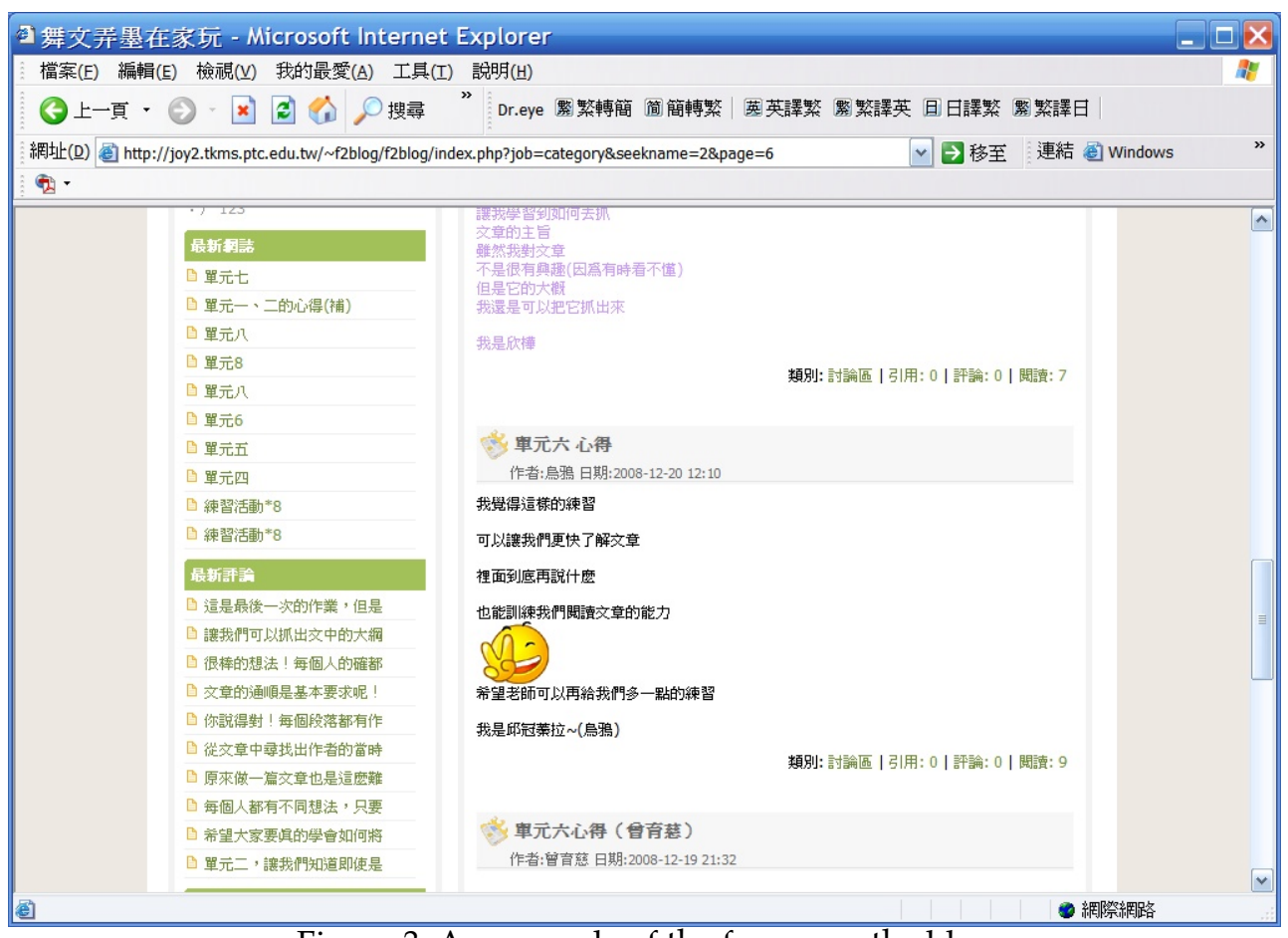

Figure 3: An example of the forum on the blog 


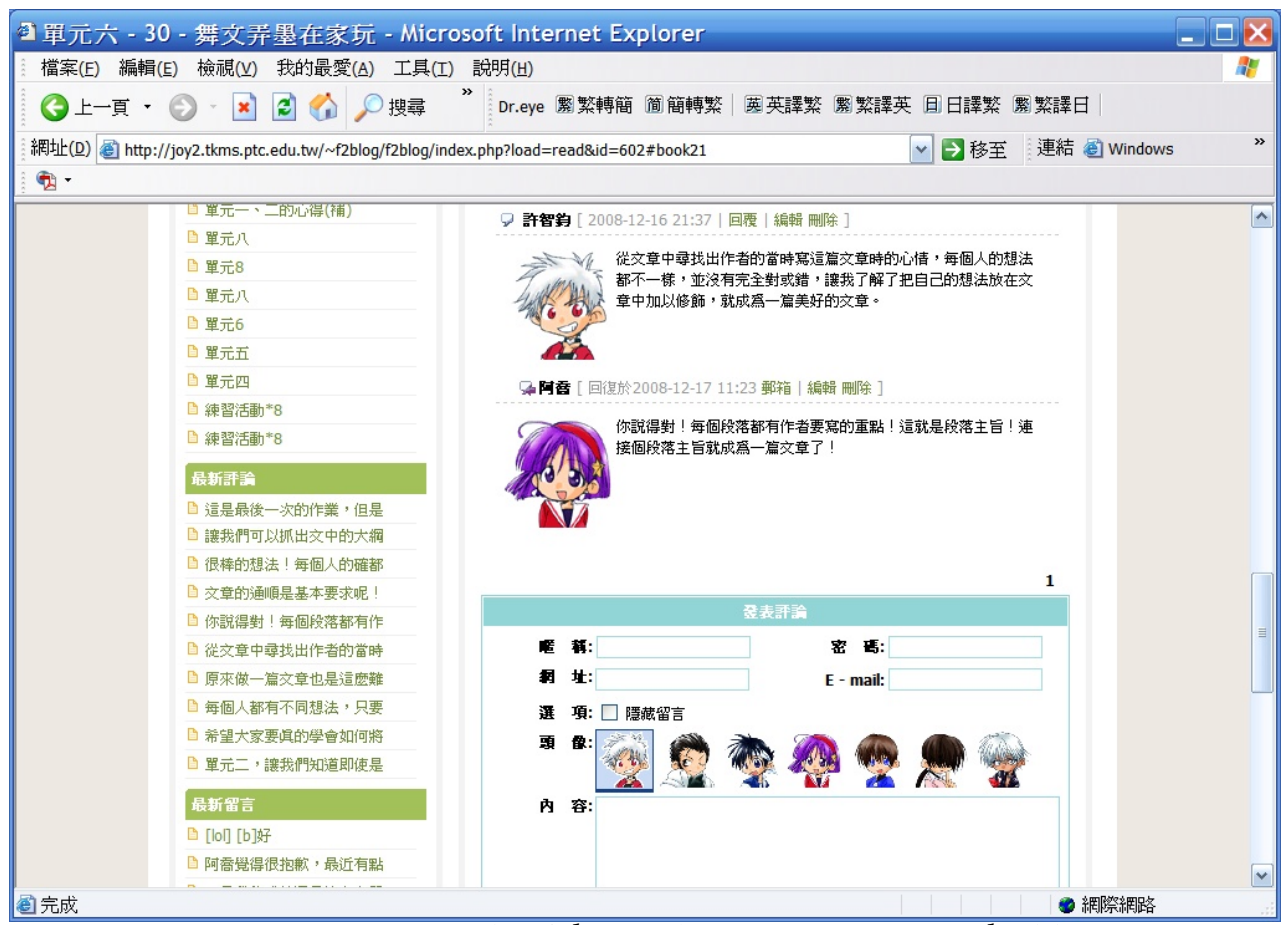

Figure 4: An example of the students' comments on the blog

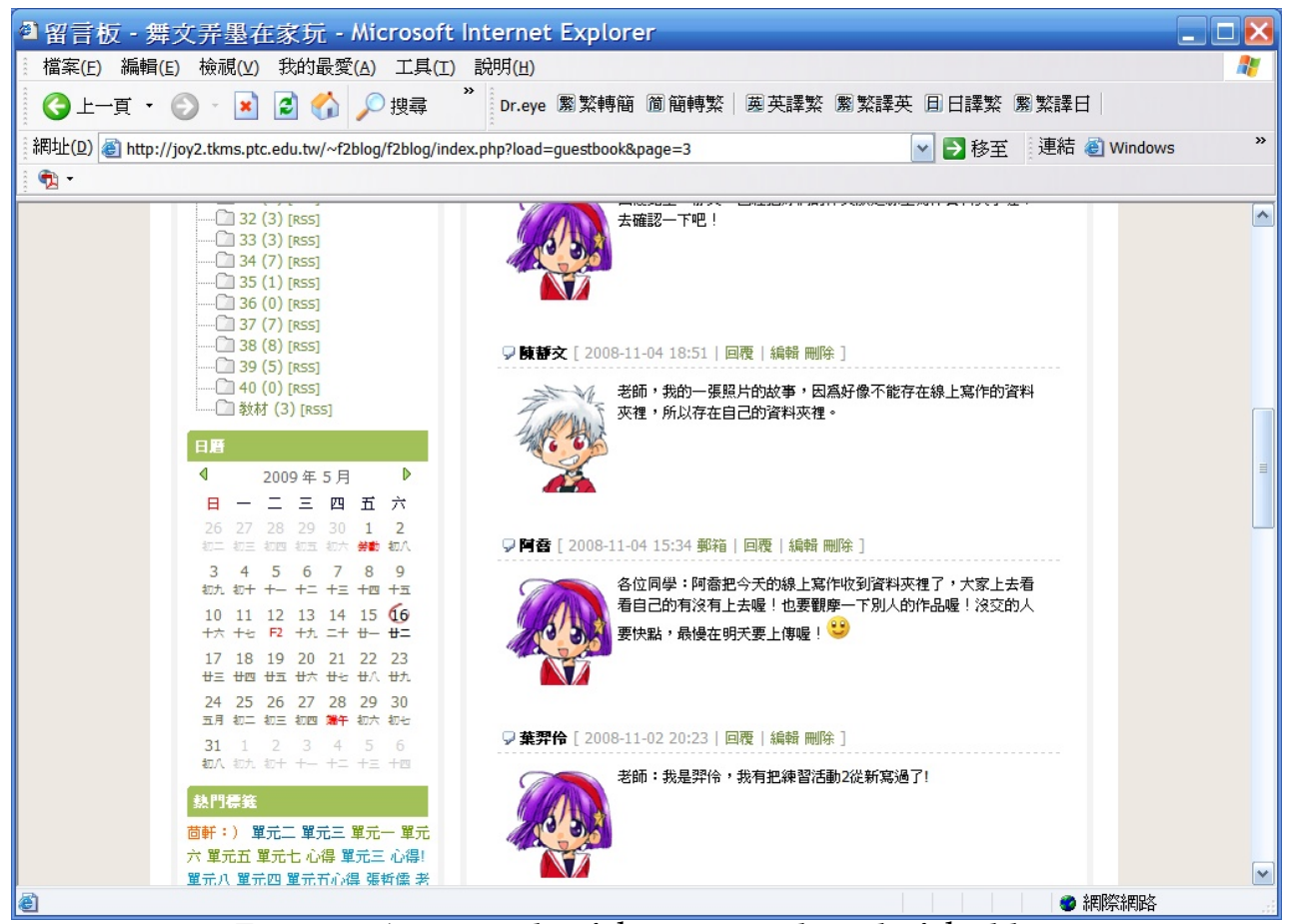

Figure 5: An example of the message board of the blog 


\section{Data processing and statistical analysis}

\section{Outcome analysis of the blogging Chinese language composition}

Both raters of the compositions were experienced high school Chinese language teachers who had experience in scoring Chinese composition for the entrance examination of public high schools. Regarding inter-rater consistency, the two raters obtained a Spearman rank correlation coefficient value of .846 $(p=.000<.05)$. This indicates that the grading consistency of the two instructors was high.

A t-test of dependent samples was administered to compare the two writing tests. The statistical results are shown in Table 2. The average of the pre-test and the post-test scores were 73.7 and 76.97 (out of 100), respectively. The statistical results show that the average post-test score is significantly higher than the average pre-test score $(p=.002<.01)$. These findings reveal that after the blogging Chinese language composition instruction period, the students' Chinese language composition ability was significantly enhanced.

Table 2: Statistical results of the pre- and post-tests

\begin{tabular}{|l|c|c|c|c|}
\hline & Mean & Standard deviation & $\mathrm{t}$ value & $\mathrm{p}$ value \\
\hline Pre-test & 73.700 & 5.680 & $-3.390^{* *}$ & .002 \\
\hline Post-test & 76.975 & 7.790 & & \\
\hline${ }^{* *} p<.01$ & \multicolumn{4}{|l}{} \\
\hline
\end{tabular}

The following excerpts were obtained from a student's pre- and post-tests on Chinese language compositions. These excerpts highlight the statistically significant difference reported above.

S1: “Therefore, we should never forget bringing our camera when we go out. Thus, we will not forget the past when we grow up. We can share the pictures with others. We can take pictures when we win the games and tell our sons about the past achievement after we get married in the future. Therefore, cameras are really important." (Last paragraph of The Story of a Picture)

"Memory is magical, and it allows us to clearly memorize wonderful people and things. Therefore, we should cherish these wonderful memories. In the future, we can share them with the next generation. Our life will thus be colorful." (Last paragraph of An Unforgettable Day)

In the excerpts above, the last paragraph in the pre-test did not end properly. The S1 shifted the focus from memory to the importance of the camera, which strayed from the topic; on the post-test, the S1 finished the paragraph with a proper ending using more appealing wording.

In sum, the students became more attentive to their writing after receiving Chinese language composition instruction that utilised blogging. They made significant progress in refining sentences, arranging paragraphs, and staying on topic. In addition, the number of words significantly differed between the pre-test and post-test. In the pre-test, there were only 8 articles with less than 600 words; in the post-test, there were 32 articles with more than 600 words. This increase in length suggests that after receiving the blogging Chinese language composition instruction, participants not only made progress in the content of their writing but also had more positive attitudes toward composition. 


\section{Analysis of the students' learning satisfaction of the blogging Chinese language composition instruction}

After the experimental instruction was completed, students completed a learning satisfaction questionnaire that assessed their feelings toward the instruction for the purpose of instructional improvement.

\section{Content design of teaching materials}

Table 3: One-sample t-tests of the students' ratings of the content design of teaching materials (scale $1=$ strongly disagree to $5=$ strongly agree)

\begin{tabular}{|c|l|c|c|c|c|}
\hline \multicolumn{1}{|c|}{ Questionnaire item } & Mean & Std dev & $\mathrm{t}$ value & Sig. \\
\hline 1. & The amount of teaching materials was appropriate. & 3.77 & .71 & 6.807 & .000 \\
\hline 2. & $\begin{array}{l}\text { The degree of difficulty of the teaching materials was } \\
\text { appropriate. }\end{array}$ & 3.64 & .74 & 5.388 & .000 \\
\hline 3. & I was interested in the content of the teaching materials. & 3.59 & .91 & 4.049 & .000 \\
\hline 4. & $\begin{array}{l}\text { The description of the learning units was clear, and I } \\
\text { understood the learning topics and objectives of each unit. }\end{array}$ & 3.97 & .87 & 6.968 & .000 \\
\hline 5. & $\begin{array}{l}\text { The teaching materials in each unit were arranged in proper } \\
\text { sequences which enhanced my composition ability gradually. }\end{array}$ & 3.87 & .73 & 7.438 & .000 \\
\hline 6. & $\begin{array}{l}\text { There were clear descriptions and guidance of writing } \\
\text { practice. }\end{array}$ & 3.92 & .84 & 6.868 & .000 \\
\hline 7. & The number of practices was appropriate. & 3.72 & .79 & 5.654 & .000 \\
\hline 8. & The degree of difficulty on the practices was appropriate. & 3.59 & .78 & 4.690 & .000 \\
\hline 9. & The design of the practices was new and interesting. & 3.67 & .89 & 4.634 & .000 \\
\hline 10. & $\begin{array}{l}\text { The learning schedule (one unit every week) was } \\
\text { appropriate. }\end{array}$ & 3.77 & .96 & 5.011 & .000 \\
\hline
\end{tabular}

According to the results of the one-sample t-tests shown in Table 3, all ten items obtained mean scores ranging from 3.59 to 3.92, with significant $p$ values of .000 . This indicates that the students were moderately satisfied with the content design of the teaching materials. The reasons for low satisfaction with these items is likely that the design of teaching materials is more rigid and cannot trigger students' interest and that students are not satisfied with the degree of difficulty of the practices. Therefore, the content and degree of difficulty of teaching materials and the degree of difficulty of practices should be improved.

\section{The blogging Chinese language composition instruction}

Table 4: One-sample t-tests of students' ratings of the blogging composition instruction (scale $1=$ strongly disagree to $5=$ strongly agree)

\begin{tabular}{|c|l|c|c|c|c|}
\hline \multicolumn{1}{|c|}{ Questionnaire item } & Mean & Std dev & t value & Sig. \\
\hline 1. & $\begin{array}{l}\text { I am more interested in learning Chinese language } \\
\text { composition through blogging. }\end{array}$ & 3.52 & 1.10 & 2.919 & .006 \\
\hline 2. & $\begin{array}{l}\text { The functions of the blogging Chinese language composition } \\
\text { website were easy to use. }\end{array}$ & 3.77 & 1.06 & 4.520 & .000 \\
\hline 3. & $\begin{array}{l}\text { The ability to read other students' work will enhance our } \\
\text { Chinese language composition ability. }\end{array}$ & 3.92 & .90 & 6.406 & .000 \\
\hline 4. & $\begin{array}{l}\text { Sharing what we learn in the forum will enhance our Chinese } \\
\text { language composition ability. }\end{array}$ & 3.92 & .84 & 6.868 & .000 \\
\hline 5. & $\begin{array}{l}\text { I feel a sense of achievement after publishing my work on the } \\
\text { Chinese language composition blogs. }\end{array}$ & 3.51 & .97 & 3.302 & .002 \\
\hline
\end{tabular}


The results of the one-sample t-tests (Table 4) indicate that all five items were significant. The highest satisfaction was seen for the statements "reading others' work on the blog will enhance composition ability" and "sharing learning on forum will enhance composition ability" $(M=3.92)$; "having a sense of achievement after publishing work on the blog" showed the least satisfaction $(\mathrm{M}=3.51)$. This dissatisfaction suggests that students are not interested in actively publishing their work and might consider the publication of their work as part of the assignment. Efforts should be made to improve student satisfaction with publishing within the blogging Chinese language composition instruction model.

Based on the answers to the open-ended questions regarding preference for the blogging Chinese language composition instruction, the main reasons for students' satisfaction with the blogging Chinese language composition instruction model were flexibility in learning (no specific schedule of class times), the ability to read others' work, the opportunity to gain more extracurricular knowledge, and the more creative nature of the blogging instruction compared with traditional lectures. The negative aspects of the blogging Chinese language composition instruction model, as perceived by the students, were: they already had a heavy workload and could hardly handle extracurricular learning, the learning time (one unit every week) was too short, and it was inconvenient that they had to learn with computers.

\section{Students' composition learning attitude}

Table 5: One-sample t-tests of the students' ratings on their attitudes toward composition learning (scale $1=$ strongly disagree to $5=$ strongly agree)

\begin{tabular}{|c|l|c|c|c|c|}
\hline \multicolumn{1}{|c|}{ Questionnaire item } & Mean & Std dev & $\mathrm{t}$ value & Sig. \\
\hline 1. & $\begin{array}{l}\text { I agree that entrance examinations for four-year and two-year } \\
\text { colleges should include composition. }\end{array}$ & 2.87 & 1.08 & -.741 & .463 \\
\hline 2. I expect an increase of composition courses. & 3.33 & .98 & 2.119 & .041 \\
\hline 3. & $\begin{array}{l}\text { I would like to learn writing by the blogging Chinese language } \\
\text { composition instructional model in the future. }\end{array}$ & 3.46 & 1.07 & 2.688 & .011 \\
\hline 4. & $\begin{array}{l}\text { I think that blogging composition instruction can motivate me } \\
\text { to learn. }\end{array}$ & 3.44 & 1.10 & 2.485 & .017 \\
\hline 5. $\begin{array}{l}\text { I think the practices of the blogging Chinese language } \\
\text { composition instruction can trigger my motivation to write. }\end{array}$ & 3.41 & 1.04 & 2.454 & .019 \\
\hline 6. & $\begin{array}{l}\text { I prefer the blogging Chinese language composition instruction } \\
\text { to traditional lectures. }\end{array}$ & 3.67 & 1.03 & 4.025 & .000 \\
\hline 7. & $\begin{array}{l}\text { After the blogging Chinese language composition learning, I } \\
\text { have different views and attitudes toward composition. }\end{array}$ & 3.92 & .90 & 6.406 & .000 \\
\hline
\end{tabular}

Table 5 shows the statistical results of one-sample t-tests of students' ratings of their attitude toward composition learning. Seven out of eight items were significant. The highest satisfaction was seen with the statement "after the blogging Chinese language composition learning, I have different views and attitude toward composition" $(\mathrm{M}=3.92)$, followed by the statement "I prefer the blogging Chinese language composition instruction to traditional lectures" $(\mathrm{M}=3.67)$. Students were least satisfied with the statement: "Entrance examinations of four-year and two-year colleges should include composition" ( $\mathrm{M}=2.87)$. The reason for this low satisfaction could be the pressure caused by the inclusion of composition in the exams. The second lowest rated item was "I expect to take more composition-related courses" ( $M=3.33)$. These results indicate that there is much room for improvement in using the blogging Chinese language composition instruction model to enhance students' composition learning motivation and ability. 


\section{The students' composition learning outcome}

Table 6: Statistical results of one-sample t-tests of the students' composition learning outcome (scale $1=$ strongly disagree to $5=$ strongly agree)

\begin{tabular}{|c|l|c|c|c|c|}
\hline \multicolumn{1}{|c|}{ Questionnaire item } & Mean & Std dev & t value & Sig. \\
\hline 1. & $\begin{array}{l}\text { I care about instructors' comments on my assignments on the } \\
\text { blog. }\end{array}$ & 4.13 & .80 & 8.800 & .000 \\
\hline 2. & $\begin{array}{l}\text { I usually felt satisfied with my grades for the blogging } \\
\text { composition assignments. }\end{array}$ & 3.23 & 1.11 & 1.279 & .020 \\
\hline 3. & $\begin{array}{l}\text { The blogging Chinese language composition learning helped me } \\
\text { avoid language errors in writing. }\end{array}$ & 3.87 & .83 & 6.537 & .000 \\
\hline 4. & $\begin{array}{l}\text { The blogging Chinese language composition learning enhanced } \\
\text { my use of rhetoric in writing. }\end{array}$ & 3.97 & .81 & 7.506 & .000 \\
\hline 5. & $\begin{array}{l}\text { The blogging Chinese language composition learning enhanced } \\
\text { my logical organisation in writing. }\end{array}$ & 4.00 & .76 & 8.208 & .000 \\
\hline 6. & $\begin{array}{l}\text { The blogging composition learning enhanced my use of } \\
\text { imagination in writing. }\end{array}$ & 3.97 & .81 & 8.190 & .000 \\
\hline 7. & $\begin{array}{l}\text { The blogging Chinese language composition learning enhanced } \\
\text { my control of the key points in paragraphs. }\end{array}$ & 3.77 & .93 & 5.161 & .000 \\
\hline 8. & $\begin{array}{l}\text { The blogging Chinese language composition learning enhanced } \\
\text { my control of the topic and details in writing. }\end{array}$ & 3.82 & .85 & 5.997 & .000 \\
\hline 9. & $\begin{array}{l}\text { After blogging Chinese language composition learning, I feel } \\
\text { more confident of writing. }\end{array}$ & 3.46 & 1.10 & 2.629 & .012 \\
\hline 10 & $\begin{array}{l}\text { I can finish writing tests (such as the pre- and post-tests) in the } \\
\text { allotted time. }\end{array}$ & 3.72 & .79 & 5.654 & .000 \\
\hline
\end{tabular}

Table 6 shows the statistical results of one-sample t-tests of the students' composition learning outcome. The ten statements reached statistical significance, with mean scores ranging from 3.23 to 4.13 . Students were least satisfied with item 2: "I was usually satisfied with the grades of my blogging Chinese language composition assignments" $(\mathrm{M}=3.23)$. The reason for this dissatisfaction could be the scoring penalties incurred from submission of late assignments, which resulted in lower grades. Students also reported low satisfaction with item 10: "I can finish the writing test in the allotted time" $(\mathrm{M}=3.72)$. The reason for this could be that the writing time provided for students was 50 minutes, and some students cannot finish assignments within the provided time. Grades for practice assignments, confidence in writing, and writing time are aspects of learning outcome that need to be improved.

The following conclusions can be made based on the above analyses of learning satisfaction:

1. Most students were satisfied with the content of the teaching materials and the description, guidance and design of the practice assignments. However, the content of teaching materials and the number and degree of difficulty of the practice assignments should be adjusted.

2. Most students agreed that the blogging Chinese language composition instruction platform enabled them to read each others' works and share their learning processes. However, the main webpage was dull and not flexible. Changes may attract the students to blogging Chinese language composition.

3. The students had different views on Chinese composition. They prefer the blogging Chinese language composition instructional model over traditional lectures. However, their expectations of taking more composition courses in the future were 
not significant, reflecting that students' motivation to learn Chinese composition is still not strong.

4. Most students agreed that blogging Chinese language composition learning will enhance their composition ability.

\section{The instructor's reflections}

The instructor had to respond and reflect on the eight units of teaching activities on the blog, including the blogging instruction, students' assignments, questions posted on the forum, and message board responses, to understand the students' learning attitudes and the effects of the blogging Chinese language composition instruction. Table 7 shows an example unit of the instructor's reflection and the instructor and students' interaction on the blogging composition instruction.

Table 7: An example unit of the instructor's reflection and the instructor-student interaction on the blogging composition instruction

\begin{tabular}{|c|c|c|}
\hline Learning units & $\begin{array}{l}\text { Learning situation } \\
\text { and reflection }\end{array}$ & Content of interaction \\
\hline $\begin{array}{l}\text { Week: } 1 \\
\text { Unit title: Introduction of incorrect } \\
\text { language. }\end{array}$ & $\begin{array}{l}\text { Students' learning } \\
\text { outcomes }\end{array}$ & $\begin{array}{l}\text { Learning to recognise incorrect } \\
\text { Chinese language wording. } \\
\text { Learning to recognise incorrect dialect } \\
\text { wording. }\end{array}$ \\
\hline $\begin{array}{l}\text { Learning objectives: Recognising } \\
\text { common instances of incorrect } \\
\text { wording and applying this }\end{array}$ & $\begin{array}{l}\text { Students' learning } \\
\text { shortages }\end{array}$ & $\begin{array}{l}\text { Delayed submission of assignments. } \\
\text { Finishing assignments carelessly. } \\
\text { Neglecting to upload the assignments. }\end{array}$ \\
\hline $\begin{array}{l}\text { Knowledg } \\
\text { Exercise: }\end{array}$ & \begin{tabular}{|l|} 
Instructors' $^{\prime}$ \\
reflection on key
\end{tabular} & $\begin{array}{l}\text { Encouraging students to submit the } \\
\text { assignments on time. }\end{array}$ \\
\hline $\begin{array}{l}\text { 1. Read example sentences in } \\
\text { Chinese language and in dialects. } \\
\text { 2. Find the errors in example } \\
\text { sentences. }\end{array}$ & $\begin{array}{l}\text { interactions } \\
\text { experienced }\end{array}$ & $\begin{array}{l}\text { Correcting students' Chinese language } \\
\text { and dialect wording. } \\
\text { Enhancing students' blogging } \\
\text { function operation. }\end{array}$ \\
\hline
\end{tabular}

Prior to the first week of instruction, the instructor guided students in using computers in class to practice the blog's functions, including going to the website, registering, leaving messages, and publishing articles, and confirmed that everyone knew how to operate the blog. However based on the summaries of the instructor's reflections of the blogging Chinese language composition instruction and instructor-student interaction (see Table 7), the researcher realised that the students still had difficulties operating the website when Unit 1, "recognition of incorrect language," was taught. Moreover, students sometimes submitted their assignments late or finished the assignments carelessly. The students' learning reactions and outcomes in this unit are not satisfying. This may be because dialect and Chinese language wording are not valued by students. Furthermore, computer languages significantly influence modern young people, and students do not have a correct concept of language. Therefore, to accomplish the teaching goal of the unit, the researcher should continue correcting students' wording and avoid allowing students to use incorrect language during writing practice.

In Unit 2, "judgment of rhetoric in sentences," students' learning was improved; they did not show any difficulties in operating or using the blog. As for learning content, rhetoric is not completely taught in elementary schools, and most students think rhetoric is quite difficult. However, most students are willing to learn aspects that 
trigger their interest, such as pop songs. Most students provided their favorite pop song and identified the rhetoric. Some students even proactively provided two songs and indicated the rhetoric used in the songs, demonstrating that the students enjoyed identifying rhetoric in pop songs. However, instructional methods of teaching rhetoric still need significant improvement.

The students' learning performance in Unit 3, "enhancement of sentences," was not satisfying. They made frequent mistakes in the practice assignments, indicating that the students need to improve their knowledge of syntax and their ability to recognise faulty and wordy sentences. This is likely due to the fact that students are used to incorrect wording and grammar and thus cannot modify sentences correctly. If students are used to faulty sentences, finding errors is difficult. However, there is a wide variety of faulty sentences, so it is difficult to cover all instances in one unit. Nevertheless, this aspect strongly reduces the quality of students' writing. Students need more practice in Chinese language composition class to improve.

For Unit 4, "application of imagination," students indicated their difficulties with the unit's activity on the forum; however, they still felt a sense of achievement after finishing their work. According to the assignments submitted, most students gradually became more motivated to complete the assignment well, and the learning outcome was positive. The students' learning process demonstrates that although it was difficult for them to create advertising slogans, most of them were able to finish the assignment on time and reported feeling a sense of achievement. With the instructor's constant encouragement, students started appearing motivated and inspired by reading others' work. The most significant difference between the blogging Chinese language composition instructional model and traditional instruction is that blogging provides an open learning space, where students' learning processes and outcomes can be assessed easily. Students' learning was shared on a forum or in their comments on others' work, which reflects the positive stimulus and can enhance students' learning motivation. However, plagiarism, which occurred during the learning process of this unit, is a disadvantage of open access to others' writing. The instructor individually warned the students about plagiarism and continued monitoring their improvement.

The writing in the activity for Unit 5, "logical organisation of sentences," was based on the previous unit. Some learners mentioned their obstacles and some expressed that they enjoyed filling in the blanks of the poem. This unit involved use of the imagination practised in the previous unit. In this unit's assignment, the students had to first read the entire modern poem provided by the instructor. After fully comprehending the meaning, the students completed the blank portion of the poem and could not change the original theme. However, the students' work demonstrated that most of them could not properly follow the poem's context and had logical problems. Their topics varied greatly and were extremely divergent from the original topic, "umbrella." There were some good submissions that remained true to the topic; however, the themes for these were still uncertain. The unsatisfying learning performance in this unit may be due to the degree of difficulty. If the instructor had indicated the original topic of the modern poem and limited students' creativity on this subject, the students may not have strayed from the main theme. In addition, the researcher demonstrated that the students could not produce a logical organisation, which was the key focus of the subsequent unit.

On the forum, most students expressed difficulty finishing the assignments for Unit 6, "cognition of key points of paragraphs." However after practising, students recognised 
the importance of the unit and most of them uploaded their assignments on time. On the forum, most students mentioned that their difficulty with writing the key points of the paragraphs was due to the fact that in school, the instructors tended to explain the aims of the example paragraphs; thus it was difficult for them to discern the themes by themselves. This shows the students' lack of reading comprehension, which was the focus of the subsequent unit. The students who could identify the aims did not properly express the aims in their writing and needed to improve their rhetoric and polish their writing. The students performed well in the part of the assignment dealing with extracting their favorite sentences and explaining the meanings. This contrast in their performance in the two parts of the assignment shows that although they had trouble grasping the aims of paragraphs, they could still comprehend single sentences.

Instruction was more successful in the activity for Unit 7, "practice of meaning analysis." Most students indicated on the forum that the example articles in practices were interesting and that they were learning how to analyse the meanings. However, a few students complained that they could not finish the practice assignment. Using two pieces of short and humorous ancient writings, the instructor trained the students in this unit to identify subjects, characters, events, key words, and sentences in the articles. Fortunately, although the learning outcome was unsatisfying in the previous unit, most of the students still followed the approach to learning meaning analysis and were able to complete the assignment. There were many excellent submissions in this unit, demonstrating that most of the students were improving their writing.

In the final unit of this experiment, "writing practice of reading comprehension," students were first asked to comprehend an article and then to produce personal reflections. Most students noted that it was not difficult to comprehend the writing but that they had trouble expressing their personal reflections. This trouble reflects that the students need to improve their ability to write creatively. The goal of this unit was to train the students to express their comprehension of different readings. The instructor selected an appropriately short classical Chinese language writing as an example article. According to the students' responses, the instructor realised that most of them comprehended and were moved by the ideas conveyed by the article. However, many students suggested on the forum that although they were extremely moved by the article, they could not express their feelings in writing. The instructor indicated that improvement in one's writing takes time and that it is praiseworthy that the students are cognitively aware of their reactions and their skills.

Due to time limitations, the researcher conducted only eight units of instruction. If the students' learning motivation can be enhanced and if students recognise the importance of writing, there will be more significant learning outcomes. In general during the learning process, most students provided positive feedback, suggesting that their learning motivation and composition abilities were enhanced after receiving instruction in the blogging Chinese language composition instructional model. Posttest results and the data acquired from the learning satisfaction questionnaire are consistent.

\section{Conclusion and suggestions}

Based on the findings of the study, some conclusions and suggestions are as follows:

1. A blogging Chinese language composition instruction model for high schools was 
established. The results show that this model can be successfully implemented with positive outcomes.

2. Adopting blogging to Chinese language composition instruction may positively enhance students' learning motivation and achievement in composition writing.

3. The participants showed a positive attitude toward the blogging Chinese language composition instruction, and most of them thought the blogging model was effective. Most students suggested that the blogging Chinese language composition instructional model was more interesting than traditional lectures. With regards to students' active learning attitudes, the blogging Chinese language composition instruction can positively enhance writing skills.

4. Based on the reflection on the unit activities of the blogging instruction and the instructor-student interaction, we can conclude that:

a. Along with positive interaction with the students, the instructor could successfully conduct the instructional activities, including wording, language cognition, the use of various rhetoric, the enhancement of sentences, the application of imagination, the logical organisation of sentences, the cognition of key points of sentences, meaning analysis, and writing of reading comprehension using a blogging Chinese language composition instructional model.

b. Most of the students indicated that Chinese language rhetoric is very difficult; however, they can learn from the blog as a way of enhancing their learning interests. For example, most students provided their favorite pop songs and identified the use of rhetoric with positive outcomes on the blog.

c. Students can easily demonstrate their learning process and present the results on the Chinese language composition instruction blog. On the blog forum, students' composition learning motivation was enhanced through commenting on others' work or presenting their learning outcomes.

d. The advantage of using blogging instruction is that students can learn from each other through posting their writings on the blog. The disadvantage is that plagiarism might occur. The instructor had to give warnings to students who plagiarised, lower their grades, and continue monitoring their work.

e. Students had mostly positive feedback regarding the learning process, which indicates that students' motivation to learn and composition abilities were enhanced after receiving Chinese language composition instruction that utilised blogging.

Suggestions for future instruction and studies are made below:

1. Collective wisdom and collaborative development: Because the teaching materials of this blogging Chinese language composition experiment were designed by the instructor herself, it might not be thorough enough. Collaboration with other Chinese language instructors to design a more thorough and complete blogging composition course could further enhance students' writing.

2. Designing personalised instruction to recognise students' personal traits: Different students have different traits. When designing learning units, the instructor should enhance the importance of learning to recognise incorrect dialect wording. If 
instructors can probe into students' traits and design proper content, the blogging instruction model will certainly be as effective as expected.

3. Using multiple instructional approaches: Composition instruction is not easy. Multiple instructional approaches can be used to trigger students' motivation and interest. If the instructor can flexibly adopt the traditional and the blogging composition instruction, the students will not only accept the instruction highly but also enhance learning outcomes. Additionally, the most effective learners are the students who participated, discussed, and observed others' work on the blog most.

4. Improving e-instruction environment and providing more assistance for instructors: E-instruction will become more common in the future; schools should improve their instructional environments and provide more assistance for instructors to smooth the transition from traditional lectures to e-instruction.

5. Flexible use of computer classroom: With the advent of the global information era, instructional methods will be gradually employed using different multimedia software. The researchers suggest that schools can flexibly adjust the use of the computer classroom. As a result, a student without a computer at home will still enjoy the same learning opportunities and convenience.

6. Broadening the significance of blog to life: Instructors should make the best use of blogging in their teaching as well as guide students to utilise blogs correctly in daily life. This will allow blogs to become a more comprehensive communication tool between school and home.

\section{References}

Brownstein, E. \& Klein, B. (2006). Blogs applications in science in science education. Journal of College Science Teaching, 35(6), 18-22.

Cheng, S. E. (2008). An action research of writing composition for 7 th grade students using peerevaluation via web blogs. Unpublished master's thesis, Tamkang University, Taipei, Taiwan.

Chou, C. \& Chang, F. S. (2002). The Internet interaction: Technology function and cognitive learning. Paper presented at the Conference of Web Learning and Library Application, Taipei, Taiwan.

Dippold, D. (2009). Peer feedback through blogs: Student and teacher perceptions in an advanced German class. ReCALL, 21, 18-36.

Dong, J. S. (2001). Introduction of Zhang Zhigong's ideal of language education. Beijing, China: People Education Publishing Company.

Du, H. S. \& Wagner, C. (2007). Learning with blogs: Enhancing cognitive and social knowledge construction. IEEE Transactions on Professional Communication, 50(4), 387-392.

Goldman, R. H., Cohen, A. P. \& Sheahan, F. (2008). Using seminar blogs to enhance student participation and learning in public health school classes. American Journal of Public Health, 98(9), 1658-1663.

Hu, C. H. (2006). A case study of misconception towards Chinese language writing in a junior high school. Unpublished master's thesis, National Sun Yat-sen University, Kaohsiung, Taiwan. 
Hung, D., Tan, S. C. \& Koh, T. S. (2006). From traditional to constructivist epistemologies: A proposed theoretical framework based on activity theory for learning communities. Journal of Interactive Learning Research, 17(1), 37-55. Chesapeake, VA: AACE.

Hwang, C. F. (2005). The persistence and probability of Chinese language writing instruction. Literature Information, 239, 81-84.

Kennedy, G. (2004). Promoting cognition in multimedia interactivity research. Journal of Interactive Learning Research, 15(1), 43-61. Norfolk, VA: AACE.

$\mathrm{Ku}, \mathrm{C}$. J. (2007). Blog and project-based learning. Teachers' Voice: National Educational Association Monthly, ROC, 197, 24-27.

Liao, S. H. (2007). The effects of peer-assessment on blogs on composition of fifth-graders. Unpublished master's thesis, National Chiayi University, Chiayi, Taiwan.

Shih, C. L. (2007). The influences of blog text-image transmission model on writing process for elementary third graders. Unpublished master's thesis, National Sun Yat-Sen University, Kaohsiung, Taiwan.

Sun, Y. W. (2008). The effects of blog-integrated writing instruction on writing attitude and writing performance for fifth and sixth graders. Unpublished master's thesis, National Taitung University, Taitung, Taiwan.

Wang, H. Y. (2007). The study of blog usage behavior - a case study of wretch. Unpublished master's thesis, National Dong Hwa University, Hualien, Taiwan.

Wang, S. C. (2006). The integration of technology and humanity - instruction of blog writing instruction. Journal of Primary Education of Tainan County, 22, 28-29.

Wu, H. J. (2009). Introduction of blogging Chinese language writing. Teachers' Voice : National Educational Association Monthly, ROC, 209, 54-57.

Yang, C. R. (2007). The application of blog in education. Network Communications Journal of Sociology. [viewed 22 Feb 2010; in Chinese] http:/ / www.nhu.edu.tw/ society/ej/61/61_25.htm

Dr Shi-Jer Lou, Associate Professor, Institute of Technology and Vocational Education National Pingtung University of Science and Technology

Shi-Chiao Wu

National Pingtung University of Science and Technology

Dr Ru-Chu Shih, Assistant Professor, Department of Modern Languages

National Pingtung University of Science and Technology

Email: vincent@npust.edu.tw

Dr Kuo-Hung Tseng, Professor, Graduate Institute of Business Management Meiho Institution of Technology 